\title{
New 1,3-Thiazoles Prepared Through Ultrasound Irradiation
}

Paulo A. T. M. Gomes (PG) ${ }^{1}$, Diogo R. M. Moreira (PG) ${ }^{1,2}$, Marcos V. O. Cardoso $(P G)^{1}$, Gevanio B. O. Filho (PG) ${ }^{1}$, Elany B. Silva (IC) ${ }^{1}$, Rajendra M. Srivastava (PQ) ${ }^{2}$ and Ana C. L. Leite (PQ) ${ }^{1^{*}}$

${ }^{1}$ Departamento de Ciencias Farmaceuticas, CCS, UFPE, Recife, $P E .{ }^{2}$ Departamento de Quimica

Fundamental, CCEN, UFPE, Recife, PE.

*e-mail corresponding author: acllb2003@yahoo.com.br

Hydrazones, thiazoles, ultrasound

\section{INTRODUCTION}

Hydrazones and $\mathrm{N}, \mathrm{S}$-heterocycles are important ligands for preparing coordination complexes. ${ }^{1}$ These ligands have also been explored as inhibitors of protozoan proteases. ${ }^{2}$ With the aim of preparing a chemical library of thiazolyl-hydrazones, we report here an convenient synthesis of these compounds using ultrasound irradiation.

\section{RESULTS AND DISCUSSION}

The target compounds (2a-I, 5a-m) were initially prepared through conventional reflux and then optimal conditions under ultrasound irradiation $(40 \mathrm{kHz}, 1.0 \mathrm{mmol}$ scale) were identified. In essential, the yields were the same under heating and ultrasound conditions, only the reaction times were shortening when performed in ultrasound (in overall, 30-60min.).

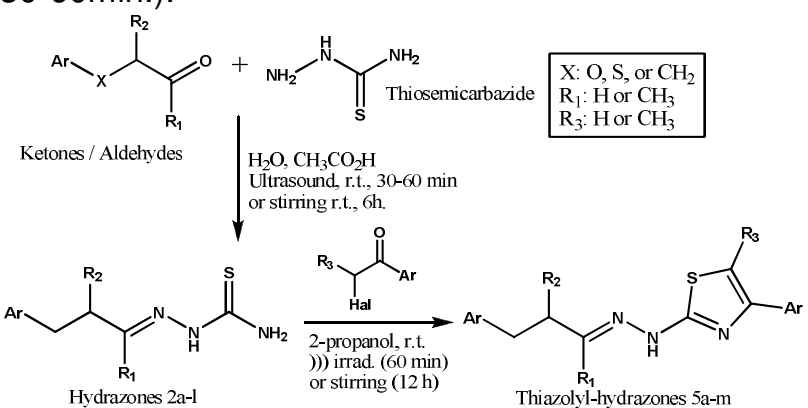

Figure 1. Synthesis of aromatic hydrazones and 1,3thiazoles.

Here, the ultrasound irradiation showed a reliable procedure for the used substrates, i.e., a large number of aromatic ketones and aldehydes in the first step as well during the step of cyclization (suitable for different $\alpha$-bromoketones). Figure 2 shows a few hydrazone and thiazole examples.

Generally speaking, we noted the success of using ultrasound irradiation is, in part, because the resulting products quickly precipitate along the reaction.

Figure 2. Examples of the aromatic hydrazones and 1,3thiazoles prepared here.

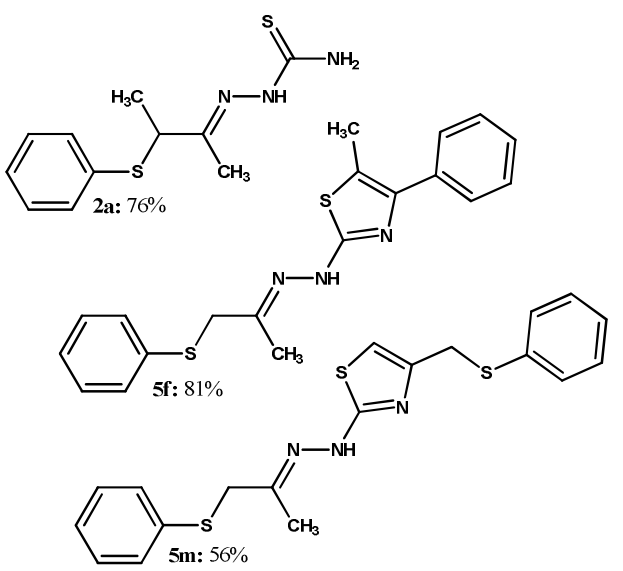

Another aim of our group is the gram-scale synthesis of these thiazoles to supply enough amounts of material for further studies of metallic coordination. A few number of these compounds were prepared at $3.0 \mathrm{mmol}$ scale (compounds 2a-c, $\mathbf{5 c - f )}$ and the procedure under ultrasound irradiation also worked well.

\section{CONCLUSION}

An easy procedure of ultrasound-mediated synthesis was employed to prepare a large number of hydrazones and thiazoles. A more detailed picture regarding this approach will be showed in the meeting.

\section{ACKNOWLEDGEMENTS}

CNPq, CAPES and FACEPE.

\section{REFERENCES}

Donnici, C. L. Bioorg. Med. Chem. 2009, 17, 503

2 Hernandes, M. Z.. Bioorg. Med. Chem. 2010, 18, 7826 